\title{
COVID-19 Impact on Undergraduate Education: Academicians' Perspective
}

\author{
Musthafa Mohamed Essa1,2,* Kabaly P. Subramanian ${ }^{3, *}$

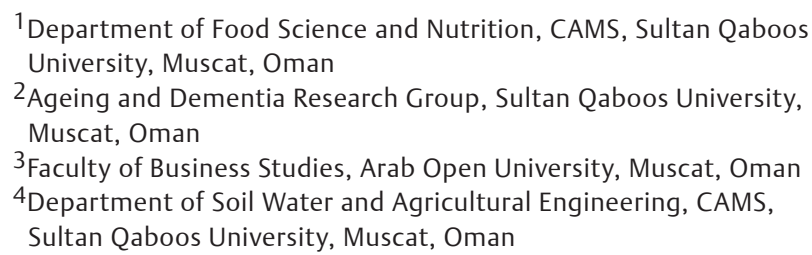

Hemanatha P. Jayasuriya ${ }^{4}$

Address for correspondence Musthafa Mohamed Essa, PhD, Department of Food Science and Nutrition, CAMS, Sultan Qaboos University, Muscat, Oman (e-mail: drmdessa@gmail.com).

J Health Allied Sci ${ }^{\mathrm{NU}}: 2020 ; 10: 138-140$

\begin{abstract}
Keywords

- COVID-19

- academics

- education

The coronavirus disease (COVID-19) pandemic has brought upon extraordinary challenges on all possible societal fronts, be it public health, education, economy, law and order, among others. In this article, we discuss the impact of COVID-19 on education from an academician's perspective. Other alternative measures are also discussed to have a smooth education.
\end{abstract}

The coronavirus disease (COVID-19) pandemic has brought upon unprecedented challenges on all possible societal fronts, be it public health, education, economy, law and order, among others. To control the pandemic, different social isolation methods have been implemented, including voluntary self-isolation, mandatory quarantine, travel restrictions, stay-at-home orders, shutdown of restaurants, theaters, churches, sports venues, museums, and other social organizations, closures of schools and universities, remote working, limitations on transportation modes such as airplanes, trains, buses, and ships, curtailing movement across borders, declaration of a state of emergency, and lockdown of entire cities, regions, and countries.

The widely implemented control measures led to unparalleled changes in every sphere of life. Multiple forms of social interaction, including education, shifted from offline to online because of enforced social isolation. For instance, in the education sector, countless universities, including Ivy League universities such as Stanford, Harvard, Princeton, Yale, and Massachusetts Institute of Technology have switched from the traditional in-person teaching to online teaching. This transformation might have led to the most significant change in education in modern history. With this one-of-a-kind shift to the cyber world, we are observing an accelerated diffusion of emerging digital technologies among educational

*These authors contributed equally to this work. institutions, teachers, students, and other stakeholders. The technology diffusion and adoption has occurred at a rapid pace (e.g., an increasing number of teachers are able to effectively teach online via online platforms such as Zoom, MS Teams, etc.). These developments, however, also bring in the concurrent challenges of cyber security and privacy issues. ${ }^{1-4}$

COVID-19 has brought upon an extraordinary change in our teaching and research community. Now, teachers have grasped the power of reaching out to thousands of students with ease using technology. It also presents a great opportunity for our researchers to investigate the phenomena of technology and societal behavior during such challenging times. This may include understanding the behavior toward technology adoption and related issues, and how these new age digital technologies help overcome challenges people face on account of social isolation, be it shopping, entertainment, among a host of other activities. Finally, a golden opportunity presents itself in the form of exploring, explaining, and predicting the behavior of human beings during a critical period, which could lead to the emergence of new theories of human behavior.

The altering of teaching methods due to the COVID-19 pandemic has, in a way, forced instructors to imbibe new technologies for delivering lectures which, in turn, has led students to better understand and focus on ideas. Instructors are now on par with the latest technologies and platforms that are being used during these times. Also, online teaching
License terms

()(1) $\Theta \circledast$ 
has aided students by way of being able to attend lectures whenever they want and ask queries at any given time, practices which are highly beneficial. Furthermore, going over lectures multiple times enable students to wholly comprehend concepts.

Having stated the possibilities of online teaching with the help of new technologies, there are, however, certain areas and components that cannot be compensated by this approach and have been severely affected globally by the COVID-19 pandemic. Two such areas in undergraduate programs are internships and graduation projects: both are considered essential components of any undergraduate curriculum.

For the internship component, undergraduate students are expected to avail of training sessions with career guidance professionals in real-time and at relevant work establishments. Some institutions and programs have initiated online internship programs; however, the success of these approaches will be program-specific or dependent on the nature of the degree program.

Similarly, with regard to the undergraduate project component, undergraduate students individually or as small groups are expected to participate in projects relevant to the field of study and supervised by an academic or a professional in the same area. These projects enable them to achieve some key learning outcomes, having engaged in hands-on activities, which are stipulated by the degree program objectives under the accreditation process of areas including health sciences, management studies, engineering, and technology, to name a few. These outcomes are clearly specified as requirements by the Accreditation Board for Engineering and Technology.
COVID-19 has impacted everyone, from children to the elderly. ${ }^{2-7}$ The above-mentioned issues are few of the major challenges that academicians and higher education institutions in specific fields of studies have to undertake in their quest to weed out the irregularities arising due to the pandemic and which may serve to negatively impact graduates. As a possible alternative, degrees which are heavily dependent on these components, and are pending completion, can be awarded after the pandemic halts.

\section{Conflict of Interest}

None declared.

\section{References}

1 Yan Z. Unprecedented pandemic, unprecedented shift, and unprecedented opportunity. Hum Behav Emerg Technol 2020;110-112

2 Fernandes AJ. Impact of COVID-19: university students' perspective. Int J Nutr Pharmacol Neurol Dis 2020;10:168-169

3 Al-Balushi B, Essa MM. The impact of COVID-19 on children-parent's perspective. Int J Nutr Pharmacol Neurol Dis 2020;10:164-165

4 Subramanian S, Mohamed S, Khanzadah T. The coronavirus' impact on education-school students' perspective. Int J Nutr Pharmacol Neurol Dis 2020;10:166-167

5 Muthuraman S, Al Haziazi M. COVID-19 impact on health, social \& economy. Int J Nutr Pharmacol Neurol Dis 2020;10:159-160

6 Prabhakar P, Punnaveetil S. COVID-19 impact-a physician's perspective. Int J Nutr Pharmacol Neurol Dis 2020;10:161-163

7 Essa MM, Hamdan H, Chidambaram SB, et al. Possible role of tryptophan and melatonin in COVID-19. Int J Tryptophan Res 2020;13:1-2 